\title{
Comprehensive Management of Daily Living Activities, behavioral and Psychological Symptoms, and Cognitive Function in Patients with Alzheimer's Disease: A Chinese Consensus on the Comprehensive Management of Alzheimer's Disease
}

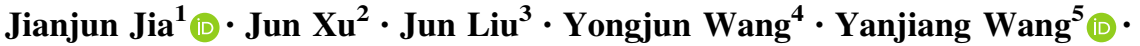 \\ Yunpeng $\mathrm{Cao}^{6} \cdot \mathrm{Qihao} \mathrm{Guo}^{7} \cdot$ Qiuming $\mathrm{Qu}^{8} \cdot$ Cuibai $\mathrm{Wei}^{9} \cdot$ Wenshi $\mathrm{Wei}^{10}$. \\ Junjian Zhang ${ }^{11} \cdot$ Enyan $\mathbf{Y u}^{12}$
}

Received: 8 September 2020/ Accepted: 6 January 2021 / Published online: 29 May 2021

(C) The Author(s) 2021, corrected publication 2021

\begin{abstract}
Alzheimer's disease (AD) is the most common cognitive disorder in the elderly. Its main clinical manifestations are cognitive decline (C), behavioral and psychological symptoms (B), and a decline in the activities of daily living (A), also known as $\mathrm{ABC}$ symptoms. Early identification and evaluation of $\mathrm{ABC}$ symptoms are helpful for establishing the accurate diagnosis, comprehensive treatment, and prognosis of AD. To guide Chinese clinical practice for optimization of the comprehensive management of AD, in 2018, The Academy of Cognitive Disorder of China gathered 22 neurologists and gerontologists in China to build a consensus on the comprehensive management of AD. Based on a review of the evidence, the consensus summarizes the pathogenesis, pathological changes, clinical manifestations, evaluation, diagnosis,
\end{abstract}

Jianjun Jia

jiajianjun301@126.com

1 Department of Neurology, The Second Medical Center, People's Liberation Army General Hospital, Beijing 100853, China

2 Department of Neurology, Beijing Tiantan Hospital, Capital Medical University, Beijing 100050, China

3 Department of Neurology, Sun Yat-sen Memorial Hospital, Sun Yat-sen University, Guangzhou 510120, China

4 Cognitive Impairment Department, Shenzhen Kangning Hospital, Shenzhen 518118, China

5 Department of Neurology, Daping Hospital, Army Medical University, Chongqing 400042, China

6 Department of Neurology, The First Hospital of China Medical University, Shenyang 210112, China

7 Department of Gerontology, Shanghai Jiaotong University Affiliated Sixth People's Hospital, Shanghai 200233, China drug and non-drug treatment, and patient care for $\mathrm{AD}$. Focus group discussion was used to establish a flowchart of comprehensive $\mathrm{ABC}$ management for $\mathrm{AD}$ patients. The new consensus provides a feasible $\mathrm{AD}$ management process for clinicians.

Keywords Alzheimer's disease - Comprehensive management $\cdot$ Activities of daily living $\cdot$ Behavioral and psychological symptoms $\cdot$ Cognitive function

Alzheimer's disease (AD) is the most common cognitive disorder in the elderly. Epidemiological surveys show that the prevalence of $\mathrm{AD}$ is $3.21 \%$ among people $\geq 65$ years in China [1]. It is estimated that the total costs of $\mathrm{AD}$ in China will be $\$ 248.71$ billion in 2020, $\$ 507.49$ billion in 2030,
8 Department of Neurology, The First Affiliated Hospital of Xi' an Jiaotong University, Xi' an 710061, China

9 Department of Neurology, Xuanwu Hospital Capital Medical University, Beijing 100053, China

10 Department of Neurology, Huadong Hospital Affiliated to Fudan University, Shanghai 200040, China

11 Department of Neurology, Zhongnan Hospital of Wuhan University, Wuhan 430071, China

12 Department of Psychology, Chinese Academy of Sciences Cancer Hospital of the University of the Chinese Academy of Sciences, Hangzhou 310022, China 
$\$ 1.00$ trillion in 2040 , and $\$ 1.89$ trillion in 2050 [2]. The number of patients who died of $\mathrm{AD}$ in the last 10 years increased by $57.8 \%$ in China, making AD the sixth leading cause of death in 2016 [3]. The major clinical manifestations of patients with $\mathrm{AD}$ include cognitive impairment (C), psychiatric and behavioral symptoms (B), and reduced activities of daily living (A), summarized as the $\mathrm{ABC}$ symptoms. Various complications occur in patients in the moderate or severe stages of $\mathrm{AD}$, requiring long-term comprehensive management and imposing heavy economic burdens on the families and society [2]. Conducting active and integrated $\mathrm{AD}$ management is hence necessary. Therefore, the Academy of Cognitive Disorder of China initiated this expert consensus on the comprehensive $\mathrm{ABC}$ management of patients with $\mathrm{AD}$, aiming to optimize the procedures of $\mathrm{AD}$ diagnosis and enhance the comprehensive management for clinicians.

\section{Estimated Demographics of AD Patient in China}

The etiologies of $\mathrm{AD}$ are still unclear. However, $\mathrm{AD}$ can be diagnosed based on the symptoms and other tests illustrated in the diagnostic criteria. The reported prevalence data provide a cost-effective way to estimate the demographics of AD patients for estimating the disease burden. The general estimated population size of $\mathrm{AD}$ has been reported in other studies, while estimation of the sizes of $\mathrm{AD}$ populations based on age stratification is needed for further precise disease management. The percentage of people with Alzheimer's dementia increases with age. People younger than 55 can also develop AD, but it is much less common and more related to genetic factors. We focused on the demographics of AD patients aged from 55 to 99 . Based on the data from the population censuses of 2010 and 2000, which reported the prevalence of $A D$ in different age groups, we estimated the $\mathrm{AD}$ population size in different age groups for 2020 and 2030. The 10-year survival rate referred to the 10 -year survival rate from 2000 to 2010 and the prevalence of $\mathrm{AD}$ for each age group was $0.23 \%$ (55-59 years), $0.55 \%$ (60-64), $1.27 \%$ (65-69), $2.73 \%$ (70-74), $5.52 \%$ (75-79), $10.44 \%$ (80-84), $18.54 \%$ (85-89), 30.86\% (90-94), and 48.19\% (95-99) [4]. The number of $\mathrm{AD}$ patients in the next decade will dramatically increase (Fig. 1).

\section{Pathogeneses and Pathological Changes in AD}

The etiologies of $\mathrm{AD}$ are still unclear. However, studies have demonstrated that its development is affected by various factors, including aging, heredity, lifestyle, and environment [5-8].

\section{Beta-amyloid and Tau}

The deposition of beta-amyloid $(A \beta)$ is believed to be the core of AD pathogenesis [9]. A new study suggests that $\mathrm{A} \beta$-dependent neuronal hyperactivation is initiated by the suppression of glutamate reuptake before plaque formation [10]. Hyperphosphorylated tau is induced by various pathological factors, and, in turn, leads to abnormal $A \beta$ accumulation.

\section{Neuroinflammation}

Neuroinflammation is associated with the neurodegeneration of $\mathrm{AD}$ and it may precede neurodegeneration. The triggers of inflammation include $A \beta$, neurodegeneration, and infection of the brain and elsewhere in the body that activates the immune system in the brain [11]. Studies with controversial conclusions have found that human herpesvirus (HHV) types 6A, 6B, and 7 are linked with $\mathrm{AD}$ [12-14]. One observational study with a 12-year follow-up showed that patients $>50$ years old with newly-diagnosed HSV-1 or HSV-2 infection have a higher risk of AD than patients with no HSV infection, and antiviral treatment can reduce the risk of dementia [15]. So, while neuroinflammation treatment might be a promising way to conquer $\mathrm{AD}$, more studies are needed.

\section{Genetics}

Several genes have been found that increase the risk of AD, while the apolipoprotein-e4 (APOE-e4) gene has the strongest impact on the risk of late-onset $\mathrm{AD}$. Those who inherit one copy of $A P O E-e 4$ have about 3 times the risk of developing $\mathrm{AD}$, while those who inherit two copies have an 8-to-12-fold risk [16-18]. Autosomal dominant familial forms of $\mathrm{AD}$ are due to mutations in one of three genes: amyloid precursor protein (APP), presenilin (PSEN) 1, and PSEN2 on chromosomes 21, 14, and 1, respectively. Genetic factors most likely determine the rate of disease progression (e.g., the brain-derived neurotrophic factor polymorphism) [19, 20]. In Han Chinese, a study showed that APOE-e4, the RS2305421 GG genotype, and the RS10498633 GT genotype are associated with the A $\beta$ plaque score, Braak neurofibrillary tangle stage, and CERAD (Consortium to Establish a Registry for Alzheimer's disease) neuritic plaque score; these results have advanced our understanding of the pathogenesis of $\mathrm{AD}$ [21]. 


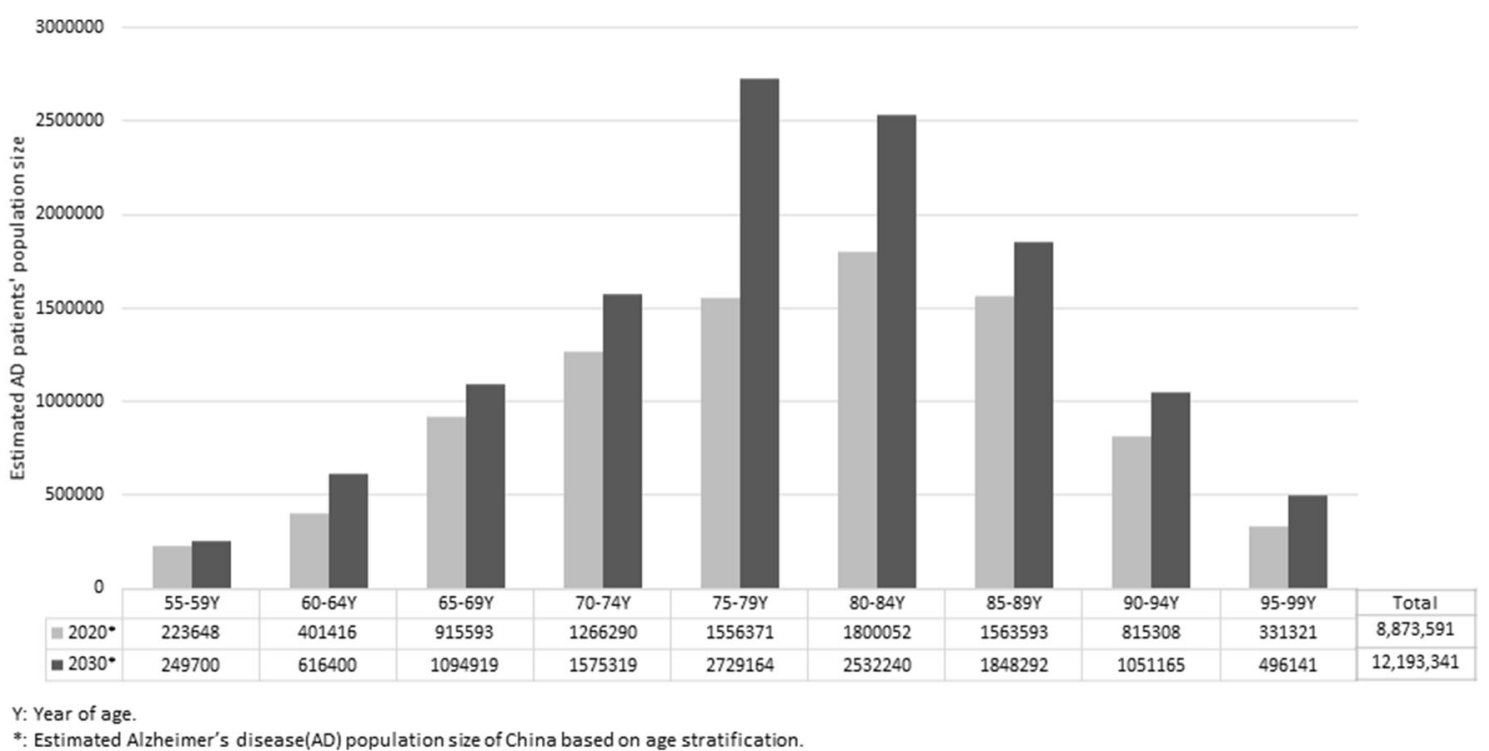

Fig. 1 Estimated Alzheimer's disease population sizes in China based on age stratification.

\section{Clinical Manifestations of AD Patients}

\section{ABC Symptoms of AD}

The clinical manifestations of $\mathrm{ABC}$ symptoms are summarized in Table 1 [22-24].

Usually, the first symptom is memory impairment, which can be manifested as forgetting and loss of the capacity to learn new information, such as repeatedly asking the same question, misplacing stuff, or even forgetting important events [25]. Language problems include not only difficulties in naming and/or finding words, grammatical and/or syntax errors, and impaired linguistic coherence and logicality but also difficulty with comprehension, writing errors, and communication disorders. Language problems consequently prevent patients from communicating with others. Executive dysfunction can appear in the early stage; this includes impairments of abilities of inference and handling complex tasks; reduction in judgment, financial management, and decisionmaking; and decreased socialization and working competence. Mild composite attention dysfunction is manifested as requiring a longer time for routine tasks than previously, as well as making mistakes in work. Difficulties in mental arithmetic or remembering and reciting new information may appear when composite attention dysfunction worsens. Visuospatial dysfunction is manifested as the absence of perception of the surrounding environment (including time, space, and people) and self-status (including name, age, and occupation), getting lost in familiar places, and being unable to recognize faces and regular objects. Social cognition impairment is manifested as personality changes and inconsiderate and unacceptable daily behaviors.
Subjective cognitive decline refers to patients believing that their memory and cognitive functions have declined compared with their previously normal status, while they are within the normal ranges measured using objective neuropsychological tests. These patients may be in the preclinical stage with AD-like physiological changes [26].

The psychiatric and behavioral symptoms can appear in any stage of $\mathrm{AD}$, although the incidence of agitation, anxiety, delusion, and abnormal behaviors is higher in patients with moderate than in those with mild AD. The mild behavioral impairments in patients with preclinical AD include emotional instability, impulse control disorder, social discomfort, and abnormal beliefs and ideas. People with mild behavioral change show increased risk of developing AD.

Activities of daily living (ADL) include basic (BADL) and intellectual activities (IADL). Feeding and bathing are significant risk factors for an increases caregiver burden [27].

\section{Associations Among the ABC Symptoms}

Cognitive impairment is associated with IADL reduction in the early stage of $\mathrm{AD}$, [28] while the worsening of cognitive function and BADL reduction are closely connected in the late stage [29]. The executive capability and personality changes may be independent risk factors in reducing IADL [30]. Therefore, ADL is important for the identification and diagnosis of cognitive impairment, and ADL assessment helps predict the risk of cognitive impairment development [31]. Also, the reduction in BADL and IADL is associated with visuospatial 
Table 1 Symptoms of reduced activities of daily living (A), psychiatric and behavioral symptoms (B), and cognitive impairment (C) of patients with Alzheimer's disease.

\begin{tabular}{|c|c|c|}
\hline Symptoms & Type & Detailed contents, items, or manifestations \\
\hline \multirow[t]{2}{*}{$\begin{array}{l}\text { Reduced activities of } \\
\text { daily living }\end{array}$} & $\begin{array}{l}\text { Basic activities of } \\
\text { daily living }\end{array}$ & Defecation, feeding, dressing/undressing, grooming, walking, and bathing \\
\hline & $\begin{array}{l}\text { Intellect activities of } \\
\text { daily living }\end{array}$ & $\begin{array}{l}\text { Using telephone, shopping, cooking, doing housework, washing clothes, taking a bus } \\
\text { independently, taking medicine, and financial independence }\end{array}$ \\
\hline \multirow[t]{12}{*}{$\begin{array}{l}\text { Psychiatric and behav- } \\
\text { ioral symptoms }\end{array}$} & Apathy/Indifference & $\begin{array}{l}\text { Decreased concern about daily activities and self-management; evidently reduced socializa- } \\
\text { tion, facial expression, verbal communication, and emotional responses; and absence of } \\
\text { motivation }\end{array}$ \\
\hline & Agitation/Offensive & $\begin{array}{l}\text { Offensive behaviors, including scratching, biting, and kicking; non-offensive body behaviors, } \\
\text { including screaming, resisting, defending, and self-protecting movements; non-offensive } \\
\text { language }\end{array}$ \\
\hline & $\begin{array}{l}\text { Depression/ } \\
\text { Dysthymia }\end{array}$ & $\begin{array}{l}\text { Negative emotions, including low mood, pessimism, sense of helplessness, and sense of } \\
\text { hopelessness }\end{array}$ \\
\hline & Anxiety & $\begin{array}{l}\text { Repeatedly asking questions or fear of being alone; some patients also fear crowds, traveling, } \\
\text { darkness, or bathing }\end{array}$ \\
\hline & $\begin{array}{l}\text { Irritability/Emotional } \\
\text { lability }\end{array}$ & Irritable, quick mood changes, and extremely impatient \\
\hline & $\begin{array}{l}\text { Hyperthymia/ } \\
\text { Euphoria }\end{array}$ & $\begin{array}{l}\text { Over-happy, feeling too good, feeling funny and laughing at things that are not interesting to } \\
\text { others, or showing scenario-inconsistent happiness }\end{array}$ \\
\hline & $\begin{array}{l}\text { Appetite and eating } \\
\text { disorders }\end{array}$ & Weight gain or loss, and changes in the flavor of enjoyed food \\
\hline & $\begin{array}{l}\text { Sleep/Nocturnal } \\
\text { behaviors }\end{array}$ & $\begin{array}{l}\text { Circadian rhythm disorder, increase in waking after sleep onset at night, and rapid eye } \\
\text { movement sleep behavior disorder }\end{array}$ \\
\hline & Hallucination & $\begin{array}{l}\text { Including visual and auditory hallucinations, with visual hallucination more common; the } \\
\text { most common visual hallucination involves seeing people who do not exist in the home or } \\
\text { seeing deceased relatives }\end{array}$ \\
\hline & Delusion & $\begin{array}{l}\text { Five typical delusions: items being stolen, living in another's house, suspicious of spouse (or } \\
\text { caregiver), being abandoned, and unfaithful spouse }\end{array}$ \\
\hline & $\begin{array}{l}\text { Abnormal motor } \\
\text { behaviors }\end{array}$ & Wandering aimlessly or following the caregiver all day, and requiring to go out at night \\
\hline & Disinhibition & $\begin{array}{l}\text { Abrupt behaviors: naturally engaging with strangers, not considering others' feelings, and } \\
\text { behaviors violating social morality }\end{array}$ \\
\hline \multirow[t]{6}{*}{ Cognitive impairment } & $\begin{array}{l}\text { Learning and } \\
\text { remembering }\end{array}$ & Immediate memory and recent memory (free recall, cued recall, and recognition) \\
\hline & Language & Expressive language (naming, fluency, grammar, and syntax) and receptive language \\
\hline & Executive capability & $\begin{array}{l}\text { Planning, decision-making, working memory, capability of feedback and correction, habit } \\
\text { inhibition, and flexibility }\end{array}$ \\
\hline & Composite attention & Sustained attention, divided attention, selective attention, and processing speed \\
\hline & $\begin{array}{l}\text { Visuoperceptual } \\
\text { function }\end{array}$ & Structure and visuoperceptual function \\
\hline & Social cognition & Emotion recognition, psychological inference, and behavior regulation \\
\hline
\end{tabular}

dysfunction [32]. Early ADL assessment should be conducted in patients with AD.

Studies have shown that the Mini-Mental Status Examination (MMSE) score is associated with the Neuropsychiatric Inventory (NPI) score, suggesting that cognitive impairment can be used to predict the behavioral and psychological symptoms of dementia (BPSD) [33]. The severity of BPSD is associated with ADL reduction; however, patients with stable BPSD do not suffer from a dramatic cognitive decline regardless of the disease stage [34].

The ABC symptoms are closely associated and interact with each other; [31-33] even in very mild AD, executive function, depression, and apathy are associated with IADL decline among female patients [35]. It is rational for clinicians to identify and assess ABC symptoms comprehensively. Early identification and assessment of ABC symptoms help to accurately diagnose and 
comprehensively treat $\mathrm{AD}$ as well as predicting the prognoses of patients.

\section{Other Phenotypes of AD}

Other phenotypes of AD include posterior cortical atrophy (PCA), logopenic progressive aphasia (LPA), frontal variant $\mathrm{AD}$, and trisomy-21 syndrome. Although their clinical manifestations vary, the pathological features suggest that they are all AD. Visuospatial and visuoperceptual dysfunctions appear in patients with PCA without evident visual causes. The capability of word expression decreases in patients with LPA, while the abilities of grammar, pronunciation, and motor speech are preserved. The speech rate of patients with LPA is low; patients frequently pause due to looking for words. The wording is generally correct despite the simple syntactic structures. Patient with LPA usually have difficulties in comprehending and reciting complex sentences. Their naming function might be damaged. Frontal symptoms, such as behavioral abnormalities, including indifference and behavioral disinhibition, occur in the early stage of frontal variant $\mathrm{AD}$. Besides, psychiatric symptoms, such as delusions, also occur. The executive functions of the patients are evidently impaired, followed by temporoparietal symptoms, such as memory deterioration, reduction in calculation ability, and spatial dysfunction. Notable mental retardation has also been found in patients with the trisomy-21 syndrome, which is accompanied by physical retardation, and specific facial features.

\section{Comprehensive Assessment of ABC Symptoms}

Currently, the assessment of $\mathrm{ABC}$ symptoms mainly depends on neuropsychological scales. Therefore, selecting the appropriate scales is critical for the early intervention and comprehensive management of $\mathrm{AD}$. The appropriate scales for early $\mathrm{AD}$ screening should have the following characteristics: (1) cover the three aspects of $A B C$ symptoms as much as possible; (2) have high sensitivity, specificity, and repeatability; and (3) be convenient and time-saving, with a time for completion $<10 \mathrm{~min}$ if possible, which allows informants or the elderly to finish the scales independently. The scales suitable for community screening mainly include the Informant Questionnaire on Dementia (such as AD8), Informant Questionnaire on Cognitive Decline in the Elderly, and Measurement of Everyday Cognition.

The commonly-used cognitive function screening scales mainly include MMSE, Montreal Cognitive Assessment (MoCA), Montreal Cognitive Assessment-Basic (MoCA$\mathrm{B})$, and the Clock Drawing Task, while the diagnostic scales mainly comprise various cognitive aspects, including memory, language, attention, visuospatial, and executive functions. The Alzheimer's Disease Assessment Scale is mainly used for the assessment of treatment efficacy, while the NPI is generally used for the assessment of BPSD. Mild behavioral abnormalities are identified using the Chinese or English version of the Mild Behavioral Impairment Checklist (the sensitivity and specificity are $86.96 \%$ and $86.00 \%$, respectively) [36]. Activity of daily living is mainly assessed using ADL and Pfeffer Functional Activities Questionnaire. Comprehensive assessment scales mainly include the Clinical Dementia Rating and ABCDementia Scale [24, 37].

Mild cognitive impairment (MCI) is the transitive state between normal cognition and dementia. MCI refers to the state of progressive impairment of memory and other cognitive functions, while the ADL is generally not affected, and the patients do not meet the diagnostic criteria of dementia [38]. Early identification and diagnosis may favor early intervention in MCI to decelerate its progression to dementia, and help the families to establish the coping strategies early [39]. The Auditory Verbal Learning Test, Animal Fluency Test, Boston Naming Test, and Trail Making Test are commonly used for the assessment of MCI.

Recommendations: (1) comprehensive, systemic assessment should be conducted to assess cognitive functions, $\mathrm{ADL}$, and BPSD; (2) the ADL scale is recommended for the assessment of ADL; the MMSE scale is recommended for the assessment of global cognition level; and the NPI scale is recommended for the assessment of BPSD (Table 2); (3) other suitable scales should be selected according to the conditions; and (4) a database of the ABC symptoms of Chinese patients with $\mathrm{AD}$ should be constructed as soon as possible, and the validity and reliability of the related scales for the diagnosis in Chinese patients should be assessed.

\section{Diagnosis of AD}

\section{Diagnostic Criteria}

The accurate diagnosis of $\mathrm{AD}$ depends on the collection of complete medical history and physical examination data, as well as the comprehensive assessment of ABC symptoms. Imaging examinations, including magnetic resonance imaging (MRI) structural imaging, cerebral positron emission computed tomography (PET), single-photon emission computed tomography (SPECT), measurement of biomarkers in blood and cerebrospinal fluid, and other auxiliary examinations, help in improving the diagnostic accuracy and further determining the subtypes. 
Table 2 Reference values of recommended tools for assessment of clinical manifestations.

\begin{tabular}{ll}
\hline Tools & Reference values \\
\hline ADL & $\begin{array}{c}\text { Full score of } 64 \text { points, }<16 \text { points is completely normal. Score of } 2-4 \text { points for single items indicates decrease of function. Score of } \\
\geq 3 \text { points on } 2 \text { or more items or a total score } \geq 22 \text { points indicate obvious dysfunction. }\end{array}$ \\
NPI & $\begin{array}{r}\text { No reference values for NPI. It is used to assess } 12 \text { behavioral disturbances. Both the frequency and severity of each behavior are } \\
\text { determined. }\end{array}$ \\
MMSE & $\begin{array}{l}\text { Full score of } 30 \text { points. For illiterate group } \leq 17 \text { points, primary school group } \leq 20 \text { points, high school or above group } \leq 24 \text { points } \\
\text { indicates cognitive impairment. }\end{array}$
\end{tabular}

ADL, Activities of daily living; NPI, Neuropsychiatric Inventory; MMSE, Mini-Mental Status Examination.

Since the issuing of the first diagnostic criteria by the US National Institute of Neurological Disorders and StrokeAlzheimer Disease and Related Disorders in 1984, seven editions of diagnostic criteria have been successively released. In recent years, the diagnostic criteria for biomarkers have attracted universal attention. However, several practical challenges are faced, including difficulties in specimen collection and high prices, in clinical practice. The National Institute on Aging and Alzheimer's Association released updated diagnostic recommendations for the preclinical, mild cognitive impairment, and dementia stages of Alzheimer's disease in 2018 to help the performance of scientific research. This research framework focuses on the diagnosis of $\mathrm{AD}$ with biomarkers in living persons for clinical research [40].

\section{Biomarkers for Diagnosis and Discrimination}

Cerebrospinal fluid and PET biomarkers of $A \beta$ and tau are highly accurate for detecting AD pathology, but the high cost, invasiveness, and low availability of these tools restrict their widespread use as clinical diagnostic tools. More and more studies have focused on blood-based biomarkers for clinical use and for facilitating clinical trial recruitment and monitoring. These studies' outcomes have provided many hints on facilitating the earlier and more accurate diagnosis of AD (Table 3).

Recommendations: (1) a review of disease history and comprehensive assessment of $\mathrm{ABC}$ symptoms should be the basis for $\mathrm{AD}$ diagnosis; (2) imaging examinations, including MRI structural imaging, cerebral PET, and SPECT, can be auxiliary examinations for diagnosing $\mathrm{AD}$; and (3) biomarker examinations, including screening for the apolipoprotein $E \varepsilon 4$ gene and measuring $A \beta$ and Tau, can be conducted if possible.

\section{Comprehensive AD Management}

Hundreds of clinical studies on drugs targeting the etiologies and pathological changes in AD have failed in recent years. Therefore, the current clinical management of
AD still focuses on managing the symptoms, delaying progression, improving the quality ,of life of patients, and reducing the burden on caregivers [45]. After three rounds of focus group discussions, we finished the $\mathrm{ABC}$ comprehensive management process instructions for $\mathrm{AD}$ patients to guide clinicians in optimizing diagnosis and treatment process based on the current situation (Fig. 2). For the different stages of $\mathrm{AD}$, different implementations of comprehensive management are also recommended (Fig. 3).

\section{Positively Manage the Risk of AD and Comorbidity}

Early intervention improves the clinical benefits for patients with $\mathrm{AD}$ [46-48]. Actively managing the risk factors, such as preventing and treating depression, quitting smoking, preventing hearing loss, stabilizing blood pressure, managing blood glucose, maintaining a reasonable diet, ensuring enough sleep, and encouraging regular physical exercise, have considerable significance in reducing and delaying the development of $\mathrm{AD}[5,49]$. After systematically reviewing the evidence of $\mathrm{AD}$ risk factor management, $\mathrm{Yu}$ et al. reported evidence-based suggestions on $\mathrm{AD}$ prevention [50].

For the elderly, comorbidities are common in $\mathrm{AD}$ patients (Table 4). [51-53] More studies have shown that some comorbidities are not only risk factors but also might be associated with the development of $\mathrm{AD}$ and affect the choice of anti-dementia medication [53, 54]. Appropriate instructions on comorbidity management are important for comprehensive management. Hypertension, hyperlipidemia, hyperglycemia, and hyperuricemia are the typical risks for AD. Studies have shown that $\mathrm{AD}$ patients with diabetes require less anti-dementia prescription than patients without diabetes. Diabetes may accelerate the course of cognitive decline and, apart from standard diabetes management, more attention should be paid to frequent checkups and anti-dementia treatments [55]. Chronic obstructive pulmonary disease (COPD) and asthma are common comorbidities in the elderly, who need long-term treatment with muscarinic antagonists. 
Table 3 Blood-based biomarkers for AD diagnosis and discrimination.

\begin{tabular}{|c|c|c|c|}
\hline Study & Cohorts & Biomarkers & Outcome \\
\hline \multirow[t]{7}{*}{$\begin{array}{c}\text { Karikari } \\
{[41]}\end{array}$} & $\begin{array}{l}\text { TRIAD and BioFIN- } \\
\text { DER-2 }\end{array}$ & Plasma p-tau181, Serum p-tau181 & Diagnosis of $\mathrm{AD}($ serum $\mathrm{AUC}=95.91 \%$, plasma $\mathrm{AUC}=90.06 \%)$ \\
\hline & TRIAD & Plasma p-tau 181 & Distinguishes $\mathrm{AD}$ from $\mathrm{A} \beta$-negative young adults $(\mathrm{AUC}=99.4 \%)$ \\
\hline & BioFINDER-2 & Plasma p-tau 181 & Distinguishes $\mathrm{AD}$ from vascular dementia $(\mathrm{AUC}=92.13 \%)$ \\
\hline & $\begin{array}{l}\text { TRIAD and BioFIN- } \\
\text { DER-2 }\end{array}$ & Plasma p-tau181 & $\begin{array}{l}\text { Distinguishes AD from other neurodegenerative disorders (AUC = } \\
82.76 \%-100 \% \text { ) }\end{array}$ \\
\hline & BioFINDER-2 & Plasma p-tau181 & Distinguishes AD from PSP or CBS (AUC $=88.47 \%$ ) \\
\hline & $\begin{array}{l}\text { TRIAD and BioFIN- } \\
\text { DER-2 }\end{array}$ & Plasma p-tau181 & Distinguishes $\mathrm{AD}$ from $\mathrm{CU}$ older adults $(\mathrm{AUC}=90.21 \%-98.24 \%)$ \\
\hline & BioFINDER-2 & Plasma p-tau 181 & Distinguishes AD from PD or MSA (AUC $=81.90 \%)$ \\
\hline \multirow[t]{9}{*}{ Jia [42] } & $\begin{array}{r}28 \mathrm{AD} / 25 \mathrm{aMCI} / 29 \\
\text { healthy controls }\end{array}$ & Plasma A $\beta 42$ & Distinguishes AD from healthy older adults $(\mathrm{AUC}=93 \%)$ \\
\hline & & Plasma $A \beta 43$ & Distinguishes AD from aMCI $(\mathrm{AUC}=83 \%)$ \\
\hline & & Plasma A $\beta 44$ & Distinguishes aMCI from healthy older adults $(\mathrm{AUC}=74 \%)$ \\
\hline & & Plasma T-tau & Distinguishes AD from healthy older adults $(\mathrm{AUC}=89 \%)$ \\
\hline & & Plasma T-tau & Distinguishes $\mathrm{AD}$ from aMCI $(\mathrm{AUC}=72 \%)$ \\
\hline & & Plasma T-tau & Distinguishes aMCI from healthy older adults $(\mathrm{AUC}=79 \%)$ \\
\hline & & Plasma p-T181-tau & Distinguishes AD from healthy older adults $(\mathrm{AUC}=88 \%)$ \\
\hline & & Plasma p-T181-tau & Distinguishes AD from aMCI $(\mathrm{AUC}=76 \%)$ \\
\hline & & Plasma p-T181-tau & Distinguishes aMCI from healthy older adults $(\mathrm{AUC}=73 \%)$ \\
\hline \multirow[t]{3}{*}{$\begin{array}{c}\text { Fotuhi } \\
{[43]}\end{array}$} & $\begin{array}{l}45 \mathrm{AD} / 36 \text { healthy } \\
\text { controls }\end{array}$ & Plasma BACE1-AS & Distinguishes full-AD from healthy older adults (AUC $=98 \%)$ \\
\hline & & Plasma BACE1-AS & Distinguishes pre-AD from healthy older adults $(\mathrm{AUC}=89 \%)$ \\
\hline & & Plasma BACE1-AS & $\begin{array}{l}\text { Distinguishes full-AD/pre-AD from healthy older adults (AUC = } \\
99 \% \text { ) }\end{array}$ \\
\hline $\begin{array}{l}\text { Nakamura } \\
{[44]}\end{array}$ & $\begin{array}{l}\text { JNCGG: } 121 \text { and } \\
\text { AIBL: } 252\end{array}$ & $\begin{array}{l}\text { Plasma APP699-711/A } \beta 1-42 \text { and } \\
\text { A } \beta 1-40 / A \beta 1-42\end{array}$ & $\begin{array}{l}\text { Distinguishes brain } \mathrm{A} \beta \text { positive or negative }(\mathrm{AUC}=96.7 \% \text { for } \\
\text { JNCGG, } \mathrm{AUC}=94.1 \% \text { for AIBL })\end{array}$ \\
\hline
\end{tabular}

AUC, area under the receiver operating characteristic curve; TRIAD, 27 young adults, 113 cognitively unimpaired older adults, 45 MCI, 33 AD, 8 FTD; BioFINDER-2, 337 cognitively unimpaired older adults, 191 MCI, 126 AD, 18 Behavioural variant FTD or PPA, 36 PD or MSA, 12 Vascular dementia, 21 PSP or CBS; CU, cognitively unimpaired; MCI, mild cognitive impairment. FTD, frontotemporal dementia; PPA, primary progressive aphasia; PD, Parkinson's disease; MSA, multiple systems atrophy; PSP, progressive supranuclear palsy; CBS, corticobasal syndrome; BACE1-AS, beta-amyloid cleaving enzyme 1 antisense; aMCI, amnestic mild cognitive impairment; pre-AD (MMSE $\geq 20$ ), full-AD (MMSE <20); JNCGG, Japanese National Centre for Geriatrics and Gerontology, 62CU/30MCI/29AD; AIBL, Australian Imaging, Biomarker and Lifestyle Study of Ageing, 156CU/67MCI/29AD; PIB-PET, 11C-labelled Pittsburgh compound-B positron-emission tomography.

COPD is not only associated with the behavioral disturbances of $\mathrm{AD}$ patients, but also with the development of cognitive deficits and frontal deficits. Due to potential pharmacodynamic interaction between muscarinic antagonists and acetylcholinesterase inhibitors (AChEIs), AD patients with asthma/COPD might benefit more from memantine than AChEIs [53, 56]. Osteoarthritis or other chronic non-cancer pain is associated with an elevated risk of AD-related dementia; this association is particularly pronounced in those with osteoarthritis and pain, and mood disorders may partially mediate this relationship [57, 58]. Although studies have emphasized the importance of pain control for $\mathrm{AD}$ patients, pain management is still a dilemma because of the side-effects of opioids. The elderly with moderate-to-severe pain might benefit more from opioids than nonsteroidal anti-inflammatory drugs to achieve adequate effects, especially when patients have gastrointestinal or cardiovascular disease. The risks and benefits of investigations need to be re-evaluated for $\mathrm{AD}$ patients. Epilepsy management for $\mathrm{AD}$ patients is also a tough medical task. A 10-year nationwide cohort study showed that patients with $\mathrm{AD}$ have a higher risk for epilepsy than those without $\mathrm{AD}$ (hazard ratio $=2.773,95 \%$ confidence interval 2.515-3.057) [59]. AD patients with epilepsy need anti-epileptic and anti-dementia therapy with the same priority. Although memantine should be used cautiously in patients with epilepsy, studies with a limited sample size reported that memantine has positive effects on improving the cognitive function in epileptic patients [60-62]. The benefits and risks of memantine for $\mathrm{AD}$ 


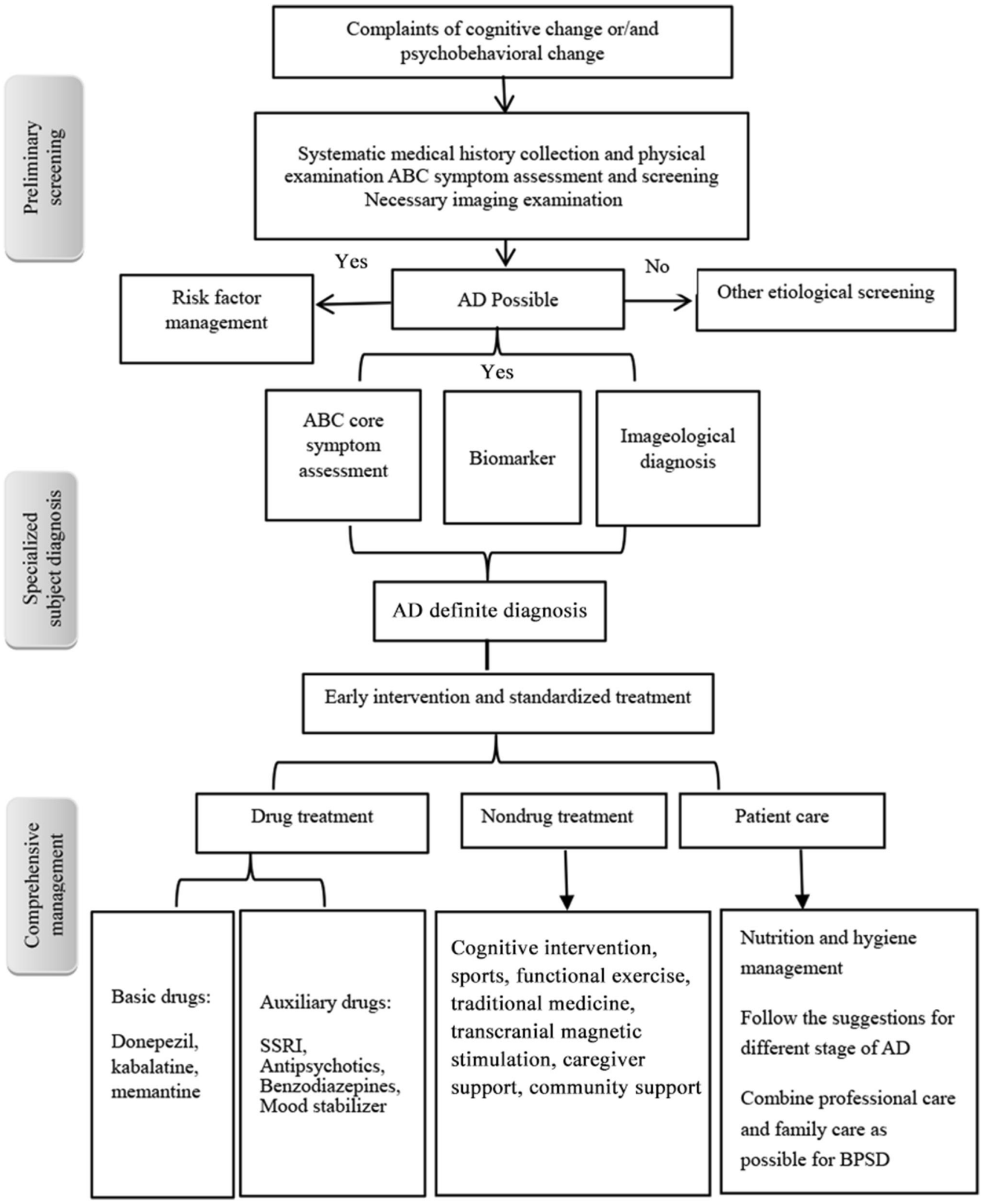

Fig. 2 Flow chart of comprehensive $A B C$ management for $A D$ patients. $\mathrm{ABC}$, daily living activities, behavioral and psychological symptoms, and cognitive function; AD, Alzheimer's disease; SSRI, selective serotonin reuptake inhibitor. BPSD, behavioral and psychological symptoms of dementia. 


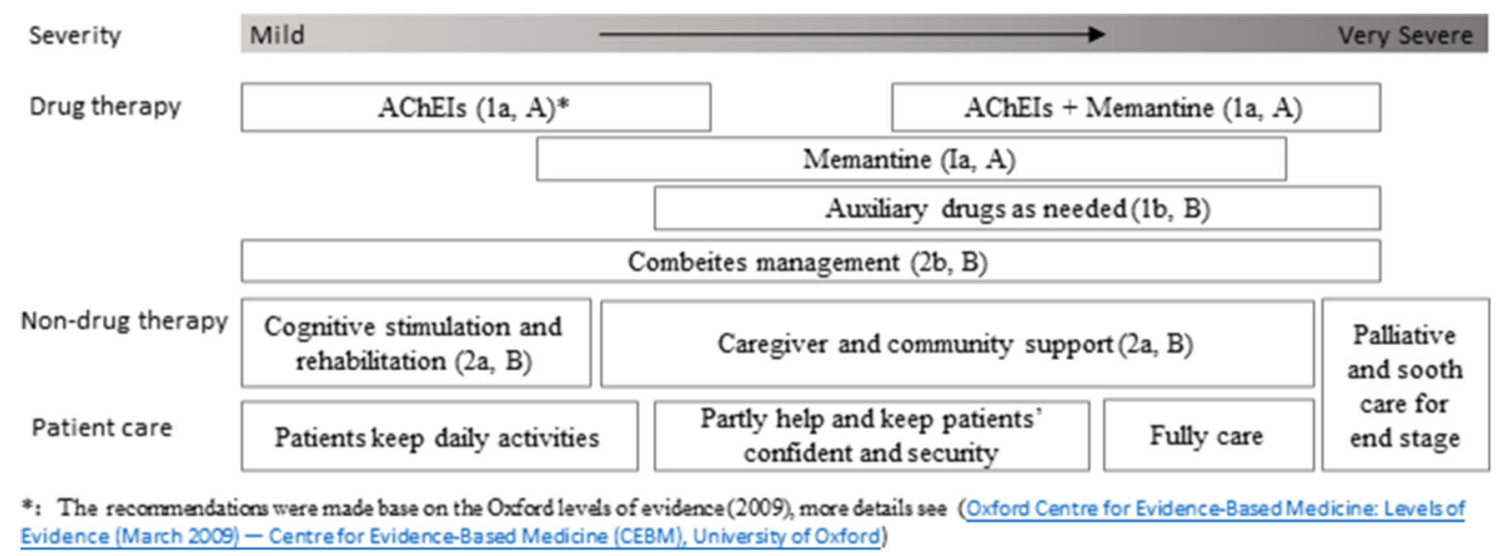

Fig. 3 Recommendations for comprehensive management at the different stages of Alzheimer's disease.

Table 4 Prevalence of comorbidities in patients with Alzheimer's disease.

\begin{tabular}{ll}
\hline Comorbidity & Prevalence \\
\hline Hypertension & $43.5 \%-55.1 \%$ \\
Diabetes mellitus & $16.5 \%-25.7 \%$ \\
Hyperlipidemia & $20.2 \%-40.6 \%$ \\
Cardiovascular disease & $22.7 \%-60.56 \%$ \\
Chronic airway disease & $10.2 \%-18.7 \%$ \\
Liver cirrhosis & $0.50 \%$ \\
Chronic renal failure & $0.80 \%-3 \%$ \\
Cancer & $1.3 \%-7.8 \%$ \\
Gout/Hyperuricemia & $5.7 \%-8.4 \%$ \\
Osteoarthritis/Pain & $10.8 \%-38.2 \%$ \\
Osteoporosis & $14.10 \%$ \\
Cerebrovascular disease & $22.80 \%$ \\
Epilepsy & $2.05 \%-11.7 \%$ \\
Parkinson's disease & $6.80 \%$ \\
Depression & $32.3 \%-47.8 \%$ \\
\hline
\end{tabular}

patients with epilepsy need to be re-evaluated for the importance of N-methyl-D-aspartic acid receptor (NMDAR) over-activation during seizures.

\section{Comprehensively Manage ABC Symptoms}

The ABC symptoms of patients with AD interact with each other. According to the principles of comprehensive treatment, the $\mathrm{ABC}$ symptoms should be taken care of comprehensively to improve the cognitive impairments, manage the psychiatric and behavioral abnormalities, ameliorate the ADL, and thus achieve greater clinical benefits for patients with AD [63]. The poor control of any ABC symptoms aggravates or influences the others.

\section{Apply Drug and Non-drug Therapies in Combination}

Appropriate drug therapy should be selected according to the current evidence and/or expert consensus. The administration of all the anti-dementia drugs must be started from a low dose and then gradually titrated to the recommended effective or maintenance dose. Combined therapy should also be considered. Anti-psychotics are usually used at low doses and for a short time. During the treatment of $\mathrm{AD}$, non-drug therapies that have certain effects in the management of $\mathrm{ABC}$ symptoms, are effective complements for drug therapies. Studies have shown that some non-drug therapies even delay the progression of AD [64-66].

\section{Stratified Patient Care of AD}

For the different stages of $\mathrm{AD}$, apart from comprehensively managing the ABC symptoms, suggestions for stratified care should be given to caregivers. Nutrition and hygiene require attention for all $\mathrm{AD}$ patients. Mild $\mathrm{AD}$ patients should have regular lives and participate in the social activities they enjoy to help them to maintain independent living activities at a high level for as long as possible. For moderate AD patients, caregivers should cultivate patients' confidence and security. For severe AD patients, caregivers should particularly focus on avoiding complications such as aspiration pneumonia, pressure sores, and deep vein thrombosis. Palliative and soothing care could be considered for end-stage AD patients [45]. BPSD care is always a tough task for caregivers. Professional care training should be provided for caregivers. Professional care and family care should be combined as much as possible for patients with BPSD. 


\section{Drug Therapy for ABC Symptom Management}

Improving cognitive impairment: (a) AChEIs: The commonly used AChEIs include donepezil, rivastigmine, galantamine, and huperzine. Evidence has shown doseeffects responses in improving the cognitive impairments of $\mathrm{AD}$ patients but the risk of adverse responses also increases with the dose of AChEIs. Therefore, the balance between the treatment efficacy and adverse responses must be considered in clinical practice [67]. (b) NMDAR antagonists: Memantine is the major drug currently used for AD treatment. A systemic review in 2019 showed that using memantine alone effectively improves the cognitive impairments. In addition, memantine is well tolerated by patients with $\mathrm{AD}$, and the incidence of adverse responses is comparable with the placebo [68].

BPSD treatment: The treatment of BPSD in patients with AD should be based on anti-dementia drugs, and antipsychotics should also be used if necessary. Both AChEIs and memantine improve BPSD. Donepezil improves the anxiety, depression, and apathy, [69] while memantine has significant efficacy in improving the delusions, agitation, offensive behaviors, and severe stereotyped behaviors [70]. Memantine also has certain effects in preventing BPSD [71]. In addition to the application of anti-dementia drugs, anti-psychotics are only considered when non-drug therapy fails, BPSD is severe, patients do not cooperate with carers, or safety issues appear [72]. Anti-psychotics should be used singly for a short time, starting from a low dose and increasing as slowly as possible. The commonly used antidepressive drugs mainly include citalopram, escitalopram oxalate, sertraline, and mirtazapine [73]. The commonly used atypical neuroleptics mainly include olanzapine, risperidone, quetiapine, and aripiprazole. Benzodiazepine drugs have certain anti-anxiety effects on patients with $\mathrm{AD}$ but more adverse responses and fewer clinical benefits than anti-psychotics. Thus, benzodiazepines should be used with caution in clinical practice [74]. Evidence regarding the effects of mood stabilizers, including valproates and lithium, on improving BPSD and cognitive impairments is still lacking [75, 76].

Preventing ADL reduction: ADL assessment is an essential factor for discriminating the severity of $\mathrm{AD}$. [29] Memantine can effectively improve the BADL and IADL [77]. The effects of AChEIs on the improvement in ADL vary. For instance, donepezil and rivastigmine improve the ADL of patients in 12 weeks, while galantamine requires a longer time to exert its effects [78].

Recommendations: (1) Both AChEIs and memantine can improve the $\mathrm{ABC}$ symptoms in patients with $\mathrm{AD}$, while combined application of the two types of drug may achieve better clinical benefits in patients with moderate or severe $\mathrm{AD}$; and (2) if BPSD cannot be managed by non-drug therapy in patients receiving anti-dementia drugs, shortterm application of low-dose anti-psychotics should be included.

\section{Non-drug Therapy for ABC Symptom Management}

Non-drug therapy mainly includes cognitive intervention, BPSD management, training in ADL, physical therapy, and movement therapy, which can be used as effective complements to drug therapy and improve the $\mathrm{ABC}$ symptoms. Due to the high operability, as well as high acceptability by patients and families, non-drug therapy is increasingly widely applied in clinical practice.

Cognitive intervention: Cognitive intervention mainly includes cognitive training, stimulation, and rehabilitation; it combines psychological theories, methods, and gamification thinking, which can restore the absent conditioned reflex in patients with $\mathrm{AD}$ in the early stage. It also comprises support for caregivers [63]. Cognitive stimulation refers to a comprehensive intervention that applies stimuli for thinking, attention, and memory in community environments to improve the cognition and social functions of patients. Cognitive stimulation continuously improves global cognitive functions and the quality of life in patients with mild and moderate AD [79]. Cognitive rehabilitation uses training, including that of memory, aiming to compensate for cognitive impairments to identify and address the requirements of individuals. Cognitive rehabilitation improves the ADL of patients and reduces the burden on caregivers [80, 81].

Non-drug therapy for BPSD: The non-drug therapy for BPSD mainly includes three types: for patients, caregivers, and the environment. (a) Treatments for patients include reminiscence therapy (discussing previous experiences), validation therapy (solving previous conflicts), simulated presence therapy (using recorded sounds of family members), aromatherapy (using aromatic plant oils), music therapy, and heliotherapy. [82] (b) Treatments for caregivers reduce the BPSD of patients with $\mathrm{AD}$ and alleviate the burden on caregivers [83]. Individualized non-drug therapy strategies are developed via training and supporting caregivers while taking the interests, cognition, and physical strength of patients into consideration [84]. (c) Treatment for the environment involves eliminating factors that induce BPSD, such as preventing hyperstimulation (such as crowded and noisy environments and irritating colors) or hypostimulation (such as lacking interaction) of patients, as well as removing potential risks (such as potentially dangerous materials).

Training in ADL: ADL training delays function loss, improves the quality of life of patients, and decreases the burden on caregivers [85, 86]. During ADL training, individualized strategies should be developed considering 
the following factors: (a) the existing skills and interests of the patients must be preserved as much as possible; (b) the instructions for training must be concise and clear; (c) the environment and equipment must be based on the detailed conditions of patients; and (d) the caregivers are trained and participate in the training of patients [87, 88].

Movement therapy: Both aerobic exercise and resistance training are associated with decreasing the risk of cognitive impairment [89]. Movement therapy increases neuroplasticity, improves $\mathrm{ABC}$ symptoms, and delays disease progression. Various methods are available, and those recommended for patients with early AD mainly include jogging, Tai Chi, and gymnastics.

Physical therapy: Physical therapy includes repetitive transcranial magnetic stimulation, transcranial direct-current stimulation, photobiomodulation, and electric shock therapy. High-frequency repetitive transcranial magnetic stimulation can help improve cognitive function and address psychological and behavioral disorders, including apathy, depression, and agitation.

Other treatments: Multimodal lifestyle intervention improves the symptoms and prognoses of patients with AD [89]. The application of advanced technologies, including artificial intelligence, game tools, virtual reality, and telemedicine, play increasingly important roles in improving the quality of life of patients, as well as reducing the burdens on the families and society.

Support for caregivers: Caregivers of patients with $\mathrm{AD}$ are under more pressure than those with other diseases, with a heavier burden and a substantially higher tendency for depression [90, 91]. Therefore, intensifying the management and support for caregivers is necessary. Further AD knowledge should be conveyed to caregivers, effective coping strategies should be developed, and a corresponding medical insurance system and social support networks should be established. These can help alleviate the burden on caregivers, increase the quality of care for patients with $\mathrm{AD}$, and improve prognoses [92, 93].

Recommendations: (1) in addition to the application of anti-dementia drugs, non-drug therapy should be given priority to manage BPSD; and (2) stratified support for caregivers is important for comprehensive management, and deserves attention.

\begin{abstract}
Acknowledgments This consensus was initiated by the Academy of Cognitive Disorder of China. Apart from the authors' contributions, we also obtained advice from another 10 experts on dementia management. The authors appreciate the contributions of Qingling Cheng, Yuliang Han, Xuemei Li, Yonghui Nie, Yuping Ning, Jinping Sun, Xuan Sun, Shanshan Wang, Zhanjun Zhang and Weiyi Zeng.
\end{abstract}

Conflict of interests The authors declare that they have no conflict of interests.
Open Access This article is licensed under a Creative Commons Attribution 4.0 International License, which permits use, sharing, adaptation, distribution and reproduction in any medium or format, as long as you give appropriate credit to the original author(s) and the source, provide a link to the Creative Commons licence, and indicate if changes were made. The images or other third party material in this article are included in the article's Creative Commons licence, unless indicated otherwise in a credit line to the material. If material is not included in the article's Creative Commons licence and your intended use is not permitted by statutory regulation or exceeds the permitted use, you will need to obtain permission directly from the copyright holder. To view a copy of this licence, visit http://creativecommons. org/licenses/by/4.0/.

\section{References}

1. Jia J, Wang F, Wei C, Zhou A, Jia X, Li F. The prevalence of dementia in urban and rural areas of China. Alzheimers Dement 2014, 10: 1-9.

2. Jia J, Wei C, Chen S, Li F, Tang Y, Qin W, et al. The cost of Alzheimer's disease in China and re-estimation of costs worldwide. Alzheimers Dement 2018, 14: 483-491.

3. Zeng XY, Qi JL, Yin P, Wang LJ, Liu YN, Liu JM, et al. Report on the burden of disease in China and provincial-level administrative regions from 1990 to 2016. Chin Circ J (In Chinese) 2018, 33: 1147-1158.

4. Chan KY, Wang W, Wu JJ, Liu L, Theodoratou E, Car J, et al. Epidemiology of Alzheimer's disease and other forms of dementia in China, 1990-2010: a systematic review and analysis. Lancet 2013, 381: 2016-2023.

5. Livingston G, Sommerlad A, Orgeta V, Costafreda SG, Huntley $\mathrm{J}$, Ames D, et al. Dementia prevention, intervention, and care. Lancet 2017, 390: 2673-2734.

6. Naj AC, Jun G, Reitz C, Kunkle BW, Perry W, Park YS, et al. Effects of multiple genetic loci on age at onset in late-onset Alzheimer disease: a genome-wide association study. JAMA Neurol 2014, 71: 1394-1404.

7. Green RC, Roberts JS, Cupples LA, Relkin NR, Whitehouse PJ, Brown $\mathrm{T}$, et al. Disclosure of APOE genotype for risk of Alzheimer's disease. N Engl J Med 2009, 361: 245-254.

8. Ostergaard SD, Mukherjee S, Sharp SJ, Proitsi P, Lotta LA, Day $\mathrm{F}$, et al. Associations between potentially modifiable risk factors and Alzheimer disease: A mendelian randomization study. PLoS Med 2015, 12: e1001841; discussion e1001841.

9. Moir RD, Lathe R, Tanzi RE. The antimicrobial protection hypothesis of Alzheimer's disease. Alzheimers Dement 2018, 14: $1602-1614$.

10. Zott B, Simon MM, Hong W, Unger F, Chen-Engerer HJ, Frosch MP, et al. A vicious cycle of beta amyloid-dependent neuronal hyperactivation. Science 2019, 365: 559-565.

11. Komaroff AL. Can Infections Cause Alzheimer Disease? JAMA 2020, 324: 239-240.

12. Readhead B, Haure-Mirande JV, Funk CC, Richards MA, Shannon $\mathrm{P}$, Haroutunian $\mathrm{V}$, et al. Multiscale analysis of independent Alzheimer's cohorts finds disruption of molecular, genetic, and clinical networks by human herpesvirus. Neuron 2018, 99: 64-82.

13. Jeong HH, Liu Z. Are HHV-6A and HHV-7 Really more abundant in Alzheimer's disease?. Neuron 2019, 104: 1034-1035.

14. Allnutt MA, Johnson K, Bennett DA, Connor SM, Troncoso JC, Pletnikova $\mathrm{O}$, et al. Human herpesvirus 6 detection in Alzheimer's disease cases and controls across multiple cohorts. Neuron 2020, 105: 1027-1035. 
15. Tzeng NS, Chung CH, Lin FH, Chiang CP, Yeh CB, Huang SY, et al. Anti-herpetic medications and reduced risk of dementia in patients with herpes simplex virus infections-a nationwide, population-based cohort study in Taiwan. Neurotherapeutics 2018, 15: 417-429.

16. Loy CT, Schofield PR, Turner AM, Kwok JB. Genetics of dementia. Lancet 2014, 383: 828-840.

17. Holtzman DM, Herz J, Bu G. Apolipoprotein E and apolipoprotein $\mathrm{E}$ receptors: normal biology and roles in Alzheimer disease. Cold Spring Harb Perspect Med 2012, 2: a006312.

18. Michaelson DM. APOE $\varepsilon 4$ : the most prevalent yet understudied risk factor for Alzheimer's disease. Alzheimers Dement 2014, 10 : 861-868.

19. Lim YY, Villemagne VL, Laws SM, Pietrzak RH, Snyder PJ, Ames $\mathrm{D}$, et al. APOE and BDNF polymorphisms moderate amyloid $\beta$-related cognitive decline in preclinical Alzheimer's disease. Mol Psychiatry 2015, 20: 1322-1328.

20. Masters CL. Major risk factors for Alzheimer's disease: age and genetics. Lancet Neurol 2020, 19: 475-476.

21. Yang Q, Chen K, Zhang H, Zhang W, Gong C, Zhang Q, et al. Correlations between single nucleotide polymorphisms, cognitive dysfunction, and postmortem brain pathology in Alzheimer's disease among Han Chinese. Neurosci Bull 2019, 35: 193-204.

22. Sachdev PS, Blacker D, Blazer DG, Ganguli M, Jeste DV, Paulsen JS, et al. Classifying neurocognitive disorders: the DSM5 approach. Nat Rev Neurol 2014, 10: 634-642.

23. Pink J, O'Brien J, Robinson L, Longson D. Dementia: assessment management and support: summary of updated NICE guidance. BMJ 2018, 361: k2438.

24. Morris JC. The Clinical Dementia Rating (CDR): current version and scoring rules. Neurology 1993, 43: 2412-2414.

25. Barnes J, Dickerson BC, Frost C, Jiskoot LC, Wolk D, van der Flier WM. Alzheimer's disease first symptoms are age dependent: Evidence from the NACC dataset. Alzheimers Dement 2015, 11: 1349-1357.

26. Jessen F, Amariglio RE, van Boxtel M, Breteler M, Ceccaldi M, Chetelat G, et al. A conceptual framework for research on subjective cognitive decline in preclinical Alzheimer's disease. Alzheimers Dement 2014, 10: 844-852.

27. Kawaharada R, Sugimoto T, Matsuda N, Tsuboi Y, Sakurai T, Ono R. Impact of loss of independence in basic activities of daily living on caregiver burden in patients with Alzheimer's disease: a retrospective cohort study. Geriatr Gerontol Int 2019, 19: 1243-1247.

28. Monaci L, Morris RG. Neuropsychological screening performance and the association with activities of daily living and instrumental activities of daily living in dementia: baseline and 18- to 24-month follow-up. Int J Geriatr Psychiatry 2012, 27 : 197-204.

29. Hall JR, Vo HT, Johnson LA, Barber RC, O’Bryant SE. The link between cognitive measures and ADLs and IADL functioning in mild Alzheimer's: what has gender got to do with it?. Int $\mathrm{J}$ Alzheimers Dis 2011, 2011: 276734.

30. Peres K, Helmer C, Amieva H, Orgogozo JM, Rouch I, Dartigues $\mathrm{JF}$, et al. Natural history of decline in instrumental activities of daily living performance over the 10 years preceding the clinical diagnosis of dementia: a prospective population-based study. J Am Geriatr Soc 2008, 56: 37-44.

31. Fauth EB, Schwartz S, Tschanz JT, Ostbye T, Corcoran C, Norton MC. Baseline disability in activities of daily living predicts dementia risk even after controlling for baseline global cognitive ability and depressive symptoms. Int J Geriatr Psychiatry 2013, 28: 597-606.

32. Kamiya M, Osawa A, Kondo I, Sakurai T. Factors associated with cognitive function that cause a decline in the level of activities of daily living in Alzheimer's disease. Geriatr Gerontol Int 2018, 18: 50-56.

33. Proitsi P, Hamilton G, Tsolaki M, Lupton M, Daniilidou M, Hollingworth $\mathrm{P}$, et al. A multiple indicators multiple causes (MIMIC) model of behavioural and psychological symptoms in dementia (BPSD). Neurobiol Aging 2011, 32: 434-442.

34. Canevelli M, Adali N, Cantet C, Andrieu S, Bruno G, Cesari M, et al. Impact of behavioral subsyndromes on cognitive decline in Alzheimer's disease: data from the ICTUS study. J Neurol 2013, 260: $1859-1865$.

35. Ikezaki H, Hashimoto M, Ishikawa T, Fukuhara R, Tanaka H, Yuki S, et al. Relationship between executive dysfunction and neuropsychiatric symptoms and impaired instrumental activities of daily living among patients with very mild Alzheimer's disease. Int J Geriatr Psychiatry 2020, 35: 877-887.

36. Cui Y, Dai S, Miao Z, Zhong Y, Liu Y, Liu L, et al. Reliability and validity of the chinese version of the mild behavioral impairment checklist for screening for Alzheimer's disease. J Alzheimers Dis 2019, 70: 747-756.

37. Mori T, Kikuchi T, Umeda-Kameyama Y, Wada-Isoe K, Kojima $\mathrm{S}$, Kagimura T, et al. ABC dementia scale: a Quick assessment tool for determining Alzheimer's disease severity. Dement Geriatr Cogn Dis Extra 2018, 8: 85-97.

38. Tay L, Lim WS, Chan M, Ali N, Mahanum S, Chew P, et al. New DSM-V neurocognitive disorders criteria and their impact on diagnostic classifications of mild cognitive impairment and dementia in a memory clinic setting. Am J Geriatr Psychiatry 2015, 23: 768-779.

39. Sanford AM. Mild Cognitive Impairment. Clin Geriatr Med 2017, 33: 325-337.

40. Jack CR Jr, Bennett DA, Blennow K, Carrillo MC, Dunn B, Haeberlein SB, et al. NIA-AA research framework: toward a biological definition of Alzheimer's disease. Alzheimers Dement 2018, 14: 535-562.

41. Karikari TK, Pascoal TA, Ashton NJ, Janelidze S, Benedet AL, Rodriguez JL, et al. Blood phosphorylated tau 181 as a biomarker for Alzheimer's disease: a diagnostic performance and prediction modelling study using data from four prospective cohorts. Lancet Neurol 2020, 19: 422-433.

42. Jia L, Qiu Q, Zhang H, Chu L, Du Y, Zhang J, et al. Concordance between the assessment of A 442 , T-tau, and P-T181-tau in peripheral blood neuronal-derived exosomes and cerebrospinal fluid. Alzheimers Dement 2019, 15: 1071-1080.

43. Fotuhi SN, Khalaj-Kondori M, Hoseinpour Feizi MA, Talebi M. Long non-coding RNA BACE1-AS may serve as an Alzheimer's disease blood-based biomarker. J Mol Neurosci 2019, 69: 351-359.

44. Nakamura A, Kaneko N, Villemagne VL, Kato T, Doecke J, Doré $\mathrm{V}$, et al. High performance plasma amyloid- $\beta$ biomarkers for Alzheimer's disease. Nature 2018, 554: 249-254.

45. Han Y, Jia J, Li X, Lv Y, Sun X, Wang S, et al. Expert consensus on the care and management of patients with cognitive impairment in China. Neurosci Bull 2020, 36: 307-320.

46. Crous-Bou M, Minguillon C, Gramunt N, Molinuevo JL. Alzheimer's disease prevention: from risk factors to early intervention. Alzheimers Res Ther 2017, 9: 71.

47. Broulikova HM, Sladek V, Arltova M, Cerny J. The potential impact of Alzheimer's disease early treatment on societal costs of care in czechia: a simulation approach. J Ment Health Policy Econ 2018, 21: 147-161.

48. Black CM, Lipton RB, Thiel E, Brouillette M, Khandker R. Relationship between treatment initiation and healthcare costs in Alzheimer's disease. J Alzheimers Dis 2019, 68: 1575-1585.

49. David ND, Lin F, Porsteinsson AP. Trajectories of neuropsychiatric symptoms and cognitive decline in mild cognitive impairment. Am J Geriatr Psychiatry 2016, 24: 70-80. 
50. Yu JT, Xu W, Tan CC, Andrieu S, Suckling J, Evangelou E, et al. Evidence-based prevention of Alzheimer's disease: systematic review and meta-analysis of 243 observational prospective studies and 153 randomised controlled trials. J Neurol Neurosurg Psychiatry 2020, 91: 1201-9.

51. Wang JH, Wu YJ, Tee BL, Lo RY. Medical comorbidity in Alzheimer's disease: a nested case-control study. J Alzheimers Dis 2018, 63: 773-781.

52. Eshetie TC, Nguyen TA, Gillam MH, Kalisch Ellett LM. Medication use for comorbidities in people with Alzheimer's disease: an australian population-based study. Pharmacotherapy 2019, 39: 1146-1156.

53. Lampela P, Tolppanen AM, Koponen M, Tanskanen A, Tiihonen $\mathrm{J}$, Hartikainen S, et al. Asthma and chronic obstructive pulmonary disease as a comorbidity and association with the choice of antidementia medication among persons with Alzheimer's disease. J Alzheimers Dis 2020, 73: 1243-1251.

54. Doraiswamy PM, Leon J, Cummings JL, Marin D, Neumann PJ. Prevalence and impact of medical comorbidity in Alzheimer's disease. J Gerontol A Biol Sci Med Sci 2002, 57: M173-177.

55. Secnik J, Cermakova P, Fereshtehnejad SM, Dannberg P, Johnell $\mathrm{K}$, Fastbom J, et al. Diabetes in a large dementia cohort: clinical characteristics and treatment from the swedish dementia registry. Diabetes Care 2017, 40: 1159-1166.

56. Tondo G, De Marchi F, Terazzi E, Prandi P, Sacchetti M, Comi $\mathrm{C}$, et al. Chronic obstructive pulmonary disease may complicate Alzheimer's disease: a comorbidity problem. Neurol Sci 2018, 39: $1585-1589$.

57. Innes KE, Sambamoorthi U. The association of osteoarthritis and related pain burden to incident Alzheimer's disease and related dementias: a retrospective cohort study of U.S medicare beneficiaries. J Alzheimers Dis 2020, 75: 789-805.

58. Khalid S, Sambamoorthi U, Innes KE. Non-cancer chronic pain conditions and risk for incident Alzheimer's disease and related dementias in community-dwelling older adults: a populationbased retrospective cohort study of united states medicare beneficiaries, 2001-2013. Int J Environ Res Public Health 2020, 17: 5454.

59. Lyou HJ, Seo KD, Lee JE, Pak HY, Lee JH. Association of Alzheimer's disease with the risk of developing epilepsy: a 10-year nationwide cohort study. Dement Neurocogn Disord 2018, 17: 156-162.

60. Oustad M, Najafi M, Mehvari J, Rastgoo A, Mortazavi Z, Rahiminejad M. Effect of donepezil and memantine on improvement of cognitive function in patients with temporal lobe epilepsy. J Res Med Sci 2020, 25: 29. https://doi.org/10.4103/ jrms.JRMS_209_19.

61. Leeman-Markowski BA, Meador KJ, Moo LR, Cole AJ, Hoch $\mathrm{DB}$, Garcia E, et al. Does memantine improve memory in subjects with focal-onset epilepsy and memory dysfunction? A randomized, double-blind, placebo-controlled trial. Epilepsy Behav 2018, 88: 315-324.

62. Marimuthu P, Varadarajan S, Krishnan M, Shanmugam S, Kunjuraman G, Ravinder JR, et al. Evaluating the efficacy of memantine on improving cognitive functions in epileptic patients receiving anti-epileptic drugs: A double-blind placebo-controlled clinical trial (Phase IIIb pilot study). Ann Indian Acad Neurol 2016, 19: 344-350.

63. Hort J, O'Brien JT, Gainotti G, Pirttila T, Popescu BO, Rektorova I, et al. EFNS guidelines for the diagnosis and management of Alzheimer's disease. Eur J Neurol 2010, 17: 1236-1248.

64. Atri A. Current and future treatments in Alzheimer's disease. Semin Neurol 2019, 39: 227-240.

65. Bahar-Fuchs A, Clare L, Woods B. (2013) Cognitive training and cognitive rehabilitation for mild to moderate Alzheimer's disease and vascular dementia. Cochrane Database Syst Rev, Cd003260.
66. Cui MY, Lin Y, Sheng JY, Zhang X, Cui RJ. Exercise intervention associated with cognitive improvement in Alzheimer's disease. Neural Plast 2018, 2018: 9234105.

67. Blanco-Silvente L, Castells X, Saez M, Barcelo MA, Garre-Olmo $\mathrm{J}$, Vilalta-Franch J, et al. Discontinuation, efficacy, and safety of cholinesterase inhibitors for Alzheimer's disease: a meta-analysis and meta-regression of 43 randomized clinical trials enrolling 16 106 patients. Int J Neuropsychopharmacol 2017, 20: 519-528.

68. McShane R, Westby MJ, Roberts E, Minakaran N, Schneider L, Farrimond LE, et al. (2019) Memantine for dementia. Cochrane Database Syst Rev, 3:Cd003154.

69. Feldman H, Gauthier S, Hecker J, Vellas B, Xu Y, Ieni JR, et al. Efficacy and safety of donepezil in patients with more severe Alzheimer's disease: a subgroup analysis from a randomized, placebo-controlled trial. Int $\mathbf{J}$ Geriatr Psychiatry 2005, 20: $559-569$.

70. Kishi T, Matsunaga S, Iwata N. The effects of memantine on behavioral disturbances in patients with Alzheimer's disease: a meta-analysis. Neuropsychiatr Dis Treat 2017, 13: 1909-1928.

71. Gauthier S, Loft H, Cummings J. Improvement in behavioural symptoms in patients with moderate to severe Alzheimer's disease by memantine: a pooled data analysis. Int $\mathrm{J}$ Geriatr Psychiatry 2008, 23: 537-545.

72. Kales HC, Lyketsos CG, Miller EM, Ballard C. Management of behavioral and psychological symptoms in people with Alzheimer's disease: an international Delphi consensus. Int Psychogeriatr 2019, 31: 83-90.

73. Sahin Cankurtaran E. Management of behavioral and psychological symptoms of dementia. Noro Psikiyatr Ars 2014, 51: 303-312.

74. Defrancesco M, Marksteiner J, Fleischhacker WW, Blasko I. (2015) Use of benzodiazepines in Alzheimer's Disease: a systematic review of literature. Int J Neuropsychopharmacol, 18: pyv055.

75. Tariot PN, Schneider LS, Cummings J, Thomas RG, Raman R, Jakimovich LJ, et al. Chronic divalproex sodium to attenuate agitation and clinical progression of Alzheimer disease. Arch Gen Psychiatry 2011, 68: 853-861.

76. Hampel H, Ewers M, Burger K, Annas P, Mortberg A, Bogstedt $\mathrm{A}$, et al. Lithium trial in Alzheimer's disease: a randomized, single-blind, placebo-controlled, multicenter 10-week study. J Clin Psychiatry 2009, 70: 922-931.

77. Li DD, Zhang YH, Zhang W, Zhao P. Meta-analysis of randomized controlled trials on the efficacy and safety of donepezil, galantamine, rivastigmine, and memantine for the treatment of Alzheimer's disease. Front Neurosci 2019, 13: 472.

78. Santoro A, Siviero P, Minicuci N, Bellavista E, Mishto M, Olivieri $\mathrm{F}$, et al. Effects of donepezil, galantamine and rivastigmine in 938 Italian patients with Alzheimer's disease: a prospective, observational study. CNS Drugs 2010, 24: 163-176.

79. Woods B, Aguirre E, Spector AE, Orrell M. (2012) Cognitive stimulation to improve cognitive functioning in people with dementia. Cochrane Database Syst Rev, Cd005562.

80. Thivierge S, Jean L, Simard M. A randomized cross-over controlled study on cognitive rehabilitation of instrumental activities of daily living in Alzheimer disease. Am J Geriatr Psychiatry 2014, 22: 1188-1199.

81. Graff MJ, Vernooij-Dassen MJ, Thijssen M, Dekker J, Hoefnagels WH, Rikkert MG. Community based occupational therapy for patients with dementia and their care givers: randomised controlled trial. BMJ 2006, 333: 1196.

82. Millan-Calenti JC, Lorenzo-Lopez L, Alonso-Bua B, de Labra C, Gonzalez-Abraldes I, Maseda A. Optimal nonpharmacological management of agitation in Alzheimer's disease: challenges and solutions. Clin Interv Aging 2016, 11: 175-184. 
83. Brodaty H, Arasaratnam C. Meta-analysis of nonpharmacological interventions for neuropsychiatric symptoms of dementia. Am J Psychiatry 2012, 169: 946-953.

84. Gitlin LN, Winter L, Burke J, Chernett N, Dennis MP, Hauck WW. Tailored activities to manage neuropsychiatric behaviors in persons with dementia and reduce caregiver burden: a randomized pilot study. Am J Geriatr Psychiatry 2008, 16: 229-239.

85. Kim SY, Yoo EY, Jung MY, Park SH, Park JH. A systematic review of the effects of occupational therapy for persons with dementia: a meta-analysis of randomized controlled trials. NeuroRehabilitation 2012, 31: 107-115.

86. Gitlin LN, Winter L, Corcoran M, Dennis MP, Schinfeld S, Hauck WW. Effects of the home environmental skill-building program on the caregiver-care recipient dyad: 6-month outcomes from the Philadelphia REACH Initiative. Gerontologist 2003, 43: 532-546.

87. Padilla R. Effectiveness of interventions designed to modify the activity demands of the occupations of self-care and leisure for people with Alzheimer's disease and related dementias. Am J Occup Ther 2011, 65: 523-531.

88. Zucchella C, Sinforiani E, Tamburin S, Federico A, Mantovani E, Bernini S, et al. The multidisciplinary approach to Alzheimer's disease and dementia. A narrative review of non-pharmacological treatment. Front Neurol 2018, 9: 1058.

89. Mendiola-Precoma J, Berumen LC, Padilla K, Garcia-Alcocer G. Therapies for prevention and treatment of Alzheimer's disease. Biomed Res Int 2016, 2016: 2589276.

90. Monteiro AMF, Santos RL, Kimura N, Baptista MAT, Dourado MCN. Coping strategies among caregivers of people with Alzheimer disease: a systematic review. Trends Psychiatry Psychother 2018, 40: 258-268.

91. Sallim AB, Sayampanathan AA, Cuttilan A, Ho R. Prevalence of mental health disorders among caregivers of patients with Alzheimer disease. J Am Med Dir Assoc 2015, 16: 1034-1041.

92. Naylor MD, Karlawish JH, Arnold SE, Khachaturian AS, Khachaturian ZS, Lee VM, et al. Advancing Alzheimer's disease diagnosis, treatment, and care: recommendations from the Ware Invitational Summit. Alzheimers Dement 2012, 8: 445-452.

93. Chiu T, Marziali E, Colantonio A, Carswell A, Gruneir M, Tang $\mathrm{M}$, et al. Internet-based caregiver support for Chinese Canadians taking care of a family member with alzheimer disease and related dementia. Can J Aging 2009, 28: 323-336. 